
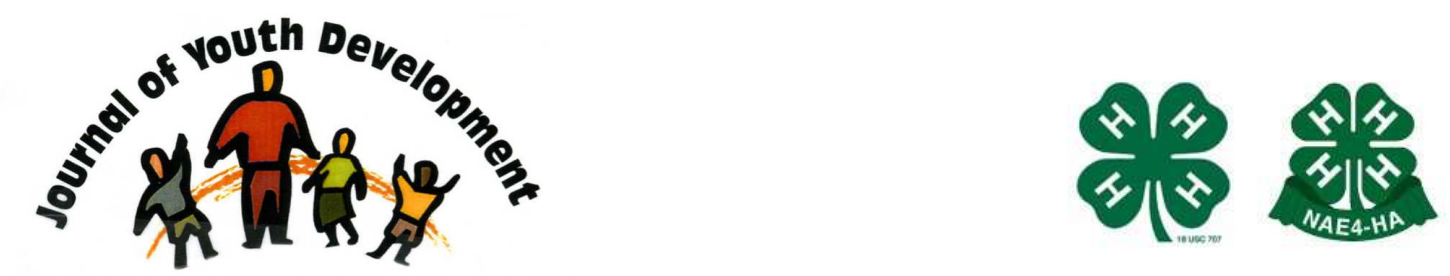

Bridging Research \& Practice

\title{
Urban Conflict Resolution: An Evidence-Based Approach
}

\author{
Lisa M. Chauveron \\ The Leadership Program \\ New York, NY 10012 \\ LISA@TLPNYC.COM
}

Amanda C. Tompkins

The Leadership Program

New York, NY 10012 


\title{
JOURNAL OF YOUTH DEVELOPMENT \\ bridging research and practice

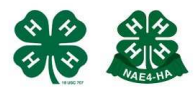

Volume 7, Number 2, Summer 2012

Article 120702PA001

\section{Urban Conflict Resolution: An Evidence-Based Approach}

Lisa M. Chauveron and Amanda C. Tompkins

The Leadership Program

\begin{abstract}
As demand for youth violence prevention programs escalates, time within traditional school day schedules and budgets are increasingly unable to accommodate them. Short, effective programs respectful of financial constraints will ensure that students in need receive quality programming. The Leadership Program's Violence Prevention Project's (VPP) 12 session school-based preventive intervention targets urban middle (6-8 grades) and high school $\left(9-10^{\text {th }}\right.$ grades) students. It reduces violence by increasing peer support, improving conflict resolution skills, and changing norms about using aggression and violence. Rated a promising model program by OJJDP, VPP uses engaging activities within core components to make change. Activities used and tools for maintaining quality is described.
\end{abstract}

\section{Introduction}

Since its inception, the youth development field has developed, instituted, and supported programs to prevent youth from participating in risky behaviors. These efforts have been successful in an array of behavioral areas, impacting local, regional, and national trends. Despite an extended period of decline followed by stability in rates of youth violence, however, the high prevalence of violent incidents remains disconcerting. The Centers for Disease Control (CDC) finds that approximately $35 \%$ of high school youth ( $44 \%$ of boys and $27 \%$ of girls) reported being in a fight within the last 12 months (2008). Additionally, 19\% of students were school-based victims of verbal or physical bullying within the last 12 months (2010).

Consequently, researchers, policy-makers, school administrators, and youth development practitioners have renewed interest in school-based violence prevention programs. This focus is justified, as meta-analyses and literature reviews indicate that prevention programs effectively reduce the types of aggressive behaviors noted above (Grove, Evans, Pastor, \& Mack, 2008).

Yet, as demand for youth violence prevention programs escalates, traditional school day schedules are increasingly unable to accommodate them. School reforms like No Child Left Behind necessitate greater focus on academics, often to the exclusion of art instruction, 
recreation, and supplemental programming. Class time for elective instruction is now as scarce as the continuously eroding budgetary allotments needed to fund them. Because schools with the highest need for youth violence prevention also traditionally have the greatest need for academic improvement and the most limited budgets, viable prevention programs must offer violence-reducing components that strike a balance between brevity and effectiveness; short, effective programs that respect budgetary constraints will ensure that students in need receive quality programming. One impactful program requiring just 12 sessions is The Leadership Program's Violence Prevention Project (VPP).

\section{Program Purpose}

VPP is a school-based preventive intervention targeted at middle and high school students in urban areas. It is designed to increase peer support, improve conflict resolution skills, and change attitudes about using aggression to reduce tolerance for violence. The program goal is to prevent conflict and violence by using skill-building exercises to improve students' conflictrelated attitudes and behaviors. Highly trained classroom-based facilitators implement 12 interactive weekly lessons for students. Each 45-minute lesson consists of an aim, warm-up, main activity, and closing. Students, typically in class sizes of 25-30, are taught through experiential active learning exercises emphasizing communication, positive socialization, and other skills necessary to succeed in school and in life.

The Office of Juvenile Justice \& Delinquency Prevention's Model Program Guide, a database of evidence-based programs implemented and evaluated with scientific rigor, rated VPP as a promising model program (2010). Evaluation results show participation in VPP is associated with improvements relative to non-participants in peer support behavior, academic self-concept, tolerance for aggressive behavior, and the use of a variety of conflict resolution skills. Specifically, relative to non-participants, middle school participants reported reduced use of verbally aggressive, physically aggressive, and antisocial conflict resolution tactics and improvements in peer support (Thompkins \& Chauveron, 2010). Additionally, relative to a comparison group, high school participants reported improvements in their academic selfconcept as well as their conflict resolution skills across a variety of areas including verbally aggressive and antisocial conflict resolution tactics.

\section{Program Theory}

VPP's curricular framework is theme-based and allows adaptation within the core curricular components to meet student and school needs (Chauveron \& Thompkins, 2010). For middle school students (6-8 grades), the core components are Introduction to Leadership, Selfaffirmation, Cooperation, Vision and Imagination, and Conflict Management. For high school students (9-10 grades), they are Introduction to Leadership, Self-Concept, Group Dynamics, Vision and Imagination, and Conflict Management. All units conclude with an arts-based group project created by each class.

In adolescence, communication skills are connected to important developmental aptitudes, including youth's perceived academic competence, quality of interpersonal relationships, and interpersonal conflict (Allen, Weissberg \& Hawkins, 1989; Borbely, Graber, Nichols, BrooksGunn, \& Botvin, 2005; Fabes \& Eisenberg, 1992; Smetana \& Gaines, 1999). To strengthen these critical life-skills, most VPP curricular lessons concentrate on explicit instruction in the communication skills essential to conflict management, including active listening, "I" 
statements, and perspective talking. Facilitators guide students through explorations of conflict resolution strategies using their improved communication skills.

In addition to the core emphasis on improving communication skills, VPP targets elements of the classroom environment. Exercises in the Conflict Management, Group Dynamics, and Cooperation target students' relationships with their peers. Positive peer relationships are key for both conflict resolution and violence prevention in adolescence, when peer influence is at its height (Gardner \& Steinberg, 2005; Hyatt \& Collins, 2000; Masten, Juvonen, \& Spatzier, 2009). Exercises in these curriculum components also target students' beliefs about the acceptability of aggressive behavior. This is especially important since prior research on the development of aggressive behavior finds youth who report that aggression is acceptable in more situations demonstrate higher levels of aggression throughout their lives (Guerra, Huesmann, \& Hanish, 1995; Henry et al, 2000; Huesmann \& Guerra, 1997).

VPP also targets academic self-concept through a variety of lessons related to academic performance and goal setting. Researchers have long noted that poor academic performers engage in more aggressive behavior while at school than better academic performers (Berkowitz, 1993; Huesmann, Eron, \& Yarmel, 1987). More recent research shows that this may be influenced by students' views of themselves as good or bad academically (Taylor, DavisKean, \& Malanchuk, 2007). VPP promotes positive academic self-concept through lessons within the Vision and Imagination and the Introduction to Leadership components related to academic performance and goal setting. All aforementioned curricular components are connected in a fun, arts-based group final project.

\section{Program Approach}

Utilizing a hybrid prevention program approach to curricular fidelity allows facilitators to account for differences in class functioning, socio-cultural relevancy, special needs, school-specific issues, and other factors essential to local and large scale implementation success (Castro, Barrera, \& Martinez, 2004; Elliott \& Mihalic, 2004; Kumpfer, Alvarado, Smith \& Bellamy, 2002). Within the core components, facilitators are required to use 2 introductory lessons; they select their remaining lessons from the component outline (Table 1). Lesson selection is based on an assessment of student, teacher, and principal centered needs (i.e., student abilities and learning styles, classroom management needs, class/school-specific violence behaviors and attitudes, cultural appropriateness). Since principal support can impact programmatic outcomes (Kam, Greenberg, \& Walls, 2003), VPP implementation includes principal involvement before classroom-based lessons begin. Then teacher-planning sessions ensue, where teacher-facilitator teams collaboratively complete a final syllabus. 
Table 1

Middle and high school component outlines

\begin{tabular}{|l|l|}
\hline Middle school outline & High school outline \\
\hline Intro to Leadership Lesson* & Intro to Leadership Lesson* \\
\hline $\begin{array}{l}\text { Real Kids Rap on Respect or } \\
\text { Setting Expectations Lesson** }\end{array}$ & Setting Expectations Lesson* \\
\hline 1 or 2 lessons from Self-Affirmation & 1 or 2 lessons from Self-Concept \\
\hline 1 or 2 lessons from Cooperation & 1 or 2 lessons from Group Dynamics \\
\hline 1 or 2 lessons from Vision and Imagination & 1 or 2 lessons from Vision and Imagination \\
\hline 4 to 6 lessons from Conflict Management & 4 to 6 lessons from Conflict Management \\
\hline Final Project Work & $\begin{array}{l}\text { (optional) } 1 \text { lesson from Social Responsibility } \\
\text { Final Project Work }\end{array}$ \\
\hline
\end{tabular}

Note: $*=$ required lesson; $* *=$ required selection from one of these two lessons.

\section{Activities}

Seasoned youth practitioners know programs must be engaging in order to make change. Utilizing fun learning activities with well-documented educational effectiveness like role-plays, games, arts incorporation, and project-based learning ensures high participant responsiveness. Sprinkled throughout each session, these activities fit seamlessly within the VPP lesson structure. Using Pfeiffer and Jones' (1983) experiential learning cycle, facilitators create continuous threads from one experience to the next, letting learners process an activity through 5 stages of comprehension culminating with application (Figure 1).

Figure 1

The experiential learning cycle

5. Applying

Assess how to use what was learned

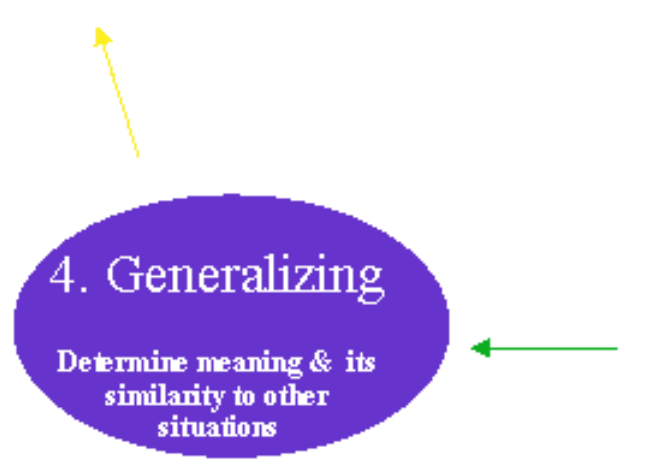

\section{(1)}
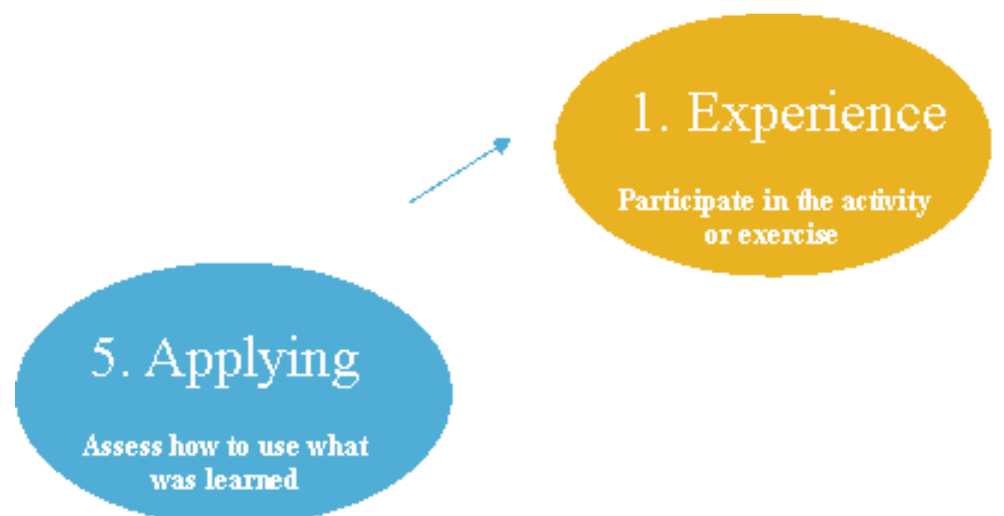
The experiential learning cycle is applied throughout the 4 segments of each lesson (aim, warm-up, main activity, and closing). Facilitators start by posting an aim, a question-phrased theme connecting the day's activities. Vocabulary terms are defined and explained to the class. Then the warm-up occurs, an ice-breaker or similar team-building group activity generally involving physical movement. Next, in the main activity, the entire class or small groups participate in fun multi-modal activities like role-plays, games, arts incorporation, trust games, cooperative work, discussions, or individual work like drawing. Exercises are modified to take advantage of "teachable moments". Finally, at the closing, the facilitator asks processing questions reflecting on the day's activities, ultimately answering the question posed by the aim. At each unit's end, students complete a final project collaboratively creating an original visual or performance artwork communicating applied VPP principles in a manner meaningful to them.

\section{Maintaining Quality}

To effectively replicate successful initiatives, program developers must employ systems dedicated to maintaining quality (Mihalic \& Irwin, 2003), including staff training and supervision, curriculum adherence and progress, and dose (the amount of designed intervention actually received by participants). With this in mind, all VPP facilitators attend a mandatory 3-day annual training with three levels--beginning, refresher, and advanced. Participants are trained in program curriculum, procedures, and processes. Optional supplemental trainings are available as booster sessions. Upon completion, facilitators receive curriculum manuals and sample lesson DVDs, a facilitation toolkit with tips, tools and resources, a facilitator's program guide describing the steps to implementation and tracking forms, a user's guide to the online database, and a class poster.

After training, facilitators are paired with a Lead Facilitator, an experienced program implementer that offers one-on-one mentoring throughout unit implementation. This linkage promotes facilitator support and VPP principle adherence. Lead Trainers conduct formal observations either annually (for returning facilitators) or bi-annually (for first-year facilitators), the results of which are discussed and action steps including coaching sessions and supplemental trainings are planned where needed. To ensure all VPP participants receive the same programmatic dose, facilitators complete weekly lesson logs indicating curricular progress and track participant attendance with an online database.

For a complete description of VPP's quality maintenance systems see Chauveron and Thompkins (2010). VPP can be implemented by schools and community organizations by following the process outlined at www.tlpnyc.com.

\section{References}

Allen, J.P., Weissberg, R.P., \& Hawkins, J.A. (1989). The relation between values and social competence in early adolescence. Developmental Psychology, 25(3), 458-464.

Berkowitz, L. (1993). Aggression: Its Causes, Consequences, and Control. Boston, MA: McGrawHill. 
Borbely, C.J., Graber, J.A., Nichols, T., Brooks-Gunn, J., \& Botvin, G.J. (2005). Sixth graders' conflict resolution in role plays with a peer, parent, and teacher. Journal of Youth and Adolescence, 34(4), 279-291.

Castro-Gonzalez, F., Barrera, M., \& Martinez, C.R. (2004). The cultural adaptation of prevention interventions: Resolving tensions between fidelity and fit. Prevention Science, 5, 41-45.

Centers for Disease Control and Prevention. (2010). Youth risk behavioral surveillance-United States, 2009. MMWR 2010;59 (No. SS-5).

Centers for Disease Control and Prevention. (2008). Youth Violence: Fact Sheet. Accessed March 15, 2010. Available at http://www.cdc.gov/ncipc/factsheets/yvfacts.htm.

Chauveron, L., \& Thompkins, A.C. (2010). The Leadership Program's Violence Prevention Project: A supplementary review of implementation fidelity from 2005-2006 through 2008-2009. Application for the National Registry of Evidence-based Programs and Practices: Violence Prevention Project.

Elliott, D.S., \& Mihalic, S. (2004). Issues in disseminating and replicating effective prevention programs. Prevention Science, 5, 47- 53.

Fabes, R.A., \& Eisenberg, N. (1992). Young children's coping with interpersonal anger. Child Development, 63, 116-128.

Gardner, M., \& Steinberg, L. (2005). Peer influence on risk taking, risk preference, and risky decision making in adolescence and adulthood: An experimental study. Developmental Psychology, 41, 625-635.

Grove, A.B., Evans, S.W., Pastor, D.A., \& Mack, S.D. (2008). A meta-analytic examination of follow-up studies of programs designed to prevent the primary symptoms of oppositional defiant and conduct disorders. Aggression and Violent Behavior, 13(3), 169-184.

Guerra, N.G., Huesmann, L.R., \& Hanish, L. (1995). The role of normative beliefs in children's social behavior. In N. Eisenberg (Ed.), Review of personality and social psychology, development and social psychology: The interface ( $p p$. 140-158). Beverly Hills, CA: Sage.

Henry, D., Guerra, N., Huesmann, R., Tolan, P., VanAcker, R., \& Eron, L. (2000). Normative influences on aggression in urban elementary school classrooms. American Journal of Community Psychology, 28(1), 59- 81.

Huesmann, L.R., Eron, L.D. \& Yarmel, P.W. (1987). Intellectual functioning and aggression. Journal of Personality and Social Psychology, 52, 232-240.

Huesmann, L.R., \& Guerra, N.G. (1997). Children's normative beliefs about aggression and aggressive behavior. Journal of Personality and Social Psychology, 72, 408-419.

Hyatt, S.L., \& Collins, L.M. (2000). Using latent transition analysis to examine the relationship between perceiver parental permissiveness and the onset of substance use. In J. S. Rose, L. Chassin, C.C. Presson, \& S. J. Sherman (Eds.), Multivariate applications in substance use research: New methods for new questions (pp 259- 288). Mahwah, NJ: Lawrence Erlbaum. 
Kam, C.M., Greenberg, M.T., \& Walls, C.T. (2003). Examining the role of implementation quality in school-based prevention using the PATHS curriculum. Promoting Alternative Thinking Skills Curriculum. Prevention Science, 4, 55-63.

Kumpfer, K., Alvarado, R., Smith, P., \& Bellamy, N. (2002). Cultural sensitivity and adaptation in family-based prevention interventions. Prevention Science, 3, 241-246.

Masten, C.L., Juvonen, J., \& Spatzier, A. (2009). Relative importance of parents and peers: Differences in academic and social behaviors at three grade levels spanning late childhood and early adolescence. Journal of Early Adolescence, 29(6), 773-799.

Mihalic, S.F., \& Irwin, K. (2003). Blueprints for violence prevention: From research to real-world settings - factors influencing the successful replication of model programs. Youth Violence and Juvenile Justice, 1(4), 307-329.

Office of Juvenile Justice \& Delinquency Prevention. (2010). Leadership Program's Violence Prevention Project. Retrieved from http://www.ojjdp.gov/mpg/mpgProgramDetails.aspx?ID=933.

Pfieffer, J.W., \& Jones, J.E. (1983). A Handbook of Structured Experiences for Human Relations Training (Vols. 1 thru 5). La Jolla, California: University Associates.

Smetana, J.G., \& Gaines, C. (1999). Adolescent-parent conflict in middle-class African American families. Child Development, 70(6), 1447-1463.

Taylor, L.D., Davis-Kean, P., \& Malanchuk, O. (2007) Self-esteem, academic self-concept, and aggression at school. Aggressive Behavior, 33, 130-136.

Thompkins, A.C. \& Chauveron, L. (2010). The Leadership Program's Violence Prevention Project: Examining program effectiveness among early and middle adolescents. Application for the National Registry of Evidence-based Programs and Practices: Violence Prevention Project.

(C) Copyright of Journal of Youth Development Bridging Research and Practice. Content may not be copied or emailed to multiple sites or posted to a listserv without copyright holder's express written permission. However, users may print, download or email articles for individual use. 